OPEN ACCESS

International Journal of

Environmental Research and

Public Health

ISSN 1660-4601

www.mdpi.com/journal/ijerph

Article

\title{
Secondhand Smoke Exposure, Indoor Smoking Bans and Smoking-Related Knowledge in China
}

\author{
Yue Jin ${ }^{1}$, Ling Wang ${ }^{1}$, Bo Lu ${ }^{2}$ and Amy K. Ferketich ${ }^{1, *}$
}

1 Division of Epidemiology, College of Public Health, The Ohio State University, 1841 Neil Ave., Columbus, OH 43210, USA; E-Mails: jin.177@osu.edu (Y.J.); wang.3347@osu.edu (L.W.)

2 Division of Biostatistics, College of Public Health, The Ohio State University, 1841 Neil Ave., Columbus, OH 43210, USA; E-Mail: lu.232@osu.edu

* Author to whom correspondence should be addressed; E-Mail: aferketich@cph.osu.edu; Tel.: +1-614-292-7326.

External Editor: Adriana Blanco Marquizo (Ms. Adriana Blanco is a staff member of the Pan American Health Organization. Her views do not necessarily represent the decisions or policies of the Pan American Health Organization.)

Received: 24 September 2014; in revised form: 3 December 2014 / Accepted: 4 December 2014 / Published: 11 December 2014

\begin{abstract}
Although previous studies have provided strong evidence that Chinese individuals are exposed to secondhand smoke (SHS) and lack knowledge of its harmful effects, there has not been an in-depth exploration of the variability in exposure and knowledge by geographic region, occupation, and socioeconomic status. The objectives of this study were to examine: (1) the demographic factors associated with the level of knowledge of the harmful effects of smoking; (2) the factors related to implementation of in-home and workplace smoking bans; and (3) geographic differences in being exposed to SHS in government buildings, healthcare facilities, restaurants, public transportations, and schools. We used data from the 2010 Global Adult Tobacco Survey-China. Chi-square tests were used for statistical analysis. The results suggested that among Chinese citizens age 15 years and older, there is poor knowledge of the harmful effects of tobacco, and knowledge varies with region and socioeconomic status. Over three-quarters of the households had no smoking restrictions, and a large percentage of workers reported working in places with no smoking ban. In public places, exposure to SHS was high, particularly in rural areas and in the Southwest. These results suggest Chinese individuals
\end{abstract}


are not well informed of smoking and SHS associated risks and are regularly exposed to SHS at home, work and public places.

Keywords: clean-indoor air laws; public smoking bans; smoke-free environments; secondhand smoke; tobacco control policies/interventions

\section{Introduction}

Secondhand smoke (SHS) exposure is known to cause adverse health outcomes among non-smokers [1]. Since there is no minimum threshold at which exposure acts to produce health effects, banning smoking in indoor places is a fundamental approach to protecting non-smokers against SHS exposure [1]. Previous studies have found that smoke-free laws in indoor places are effective at reducing SHS exposure [2,3]. In addition, knowledge about the harmful effects of SHS exposure is an important factor related in reducing SHS exposure. Several studies have indicated that people with better knowledge are more likely to protect themselves and others against SHS exposure by opening windows, establishing a smoking ban in the home, or keeping their children out of a smoking environment [4-6].

According to the World Health Organization (WHO), among the one billion smokers worldwide, 80\% live in low- and middle-income countries [7]. In China, there are over 300 million smokers, which makes it the country with the world's largest population of smokers [8]. Previous research has shown that tobacco use could cause premature death in more than one-third of males in China by 2030 [9].

Based on increasing awareness about the harmful effects of SHS exposure, many developed countries have made efforts to reduce SHS exposure in public places and in the home [10-15]. However, China's efforts to protect people from SHS exposure in public places have not been as effective [8].

Although the Chinese Government ratified the WHO's Framework Convention on Tobacco Control (FCTC) in 2005, 72\% of non-smokers aged 15 and older were still regularly exposed to SHS in 2010, with more than half exposed on a daily basis [16]. Smoking restrictions in public places are usually imposed by public policy. China's indoor smoking policies differ by region and are mostly only implemented in major cities [17]. Moreover, the policies do not include workplaces [17].

During the past decade, many studies have reported on SHS exposure in China [16,18-23]. In 2004, a cross-sectional survey, performed in six counties in China, found that only $6.3 \%$ of households had implemented a complete in-home smoking ban [21]. In 2010, a local household survey conducted in Guangdong Province, China suggested that more homes have complete smoking bans [22]. According to the 2010 Global Adult Tobacco Survey-China (GATS China), about $67.3 \%$ of adults reported someone smoked at home during past month [23]. King and colleagues used GATS data from 14 countries and examined SHS exposure by age and gender. They found that Chinese residents had relatively high exposure to SHS in the home and workplaces compared to other countries [19]. In other studies, awareness of the harmful effects of smoking and SHS exposure has been linked to a reduced risk of SHS exposure [4-6]. While previous studies have provided strong evidence that Chinese individuals are exposed to SHS and lack knowledge of its harmful effects, there has not been an in-depth 
exploration of the variability in exposure and knowledge by geographic region, occupation, and socioeconomic status. Furthering this understanding may guide the future development of effective tobacco control programs.

We used data from 2010 Global Adults Tobacco Survey-China (GATS China) to examine: (1) the demographic factors associated with the level of knowledge of the harmful effects of smoking; (2) the factors related to implementation of in-home and workplace smoking bans; and (3) geographic differences in being exposed to SHS in government buildings, healthcare facilities, restaurants, public transportations, and schools.

\section{Methods}

\subsection{Study Population}

We used data from the 2010 GATS in China, which is a nationally representative household survey of the population aged 15 years and older. As a component of Global Tobacco Surveillance System (GTSS), during 2008 and 2010 the GATS used a standardized method to monitor tobacco use and tobacco control conditions across 16 low-and-middle income countries, including China. The 2010 GATS China used a multi-stage stratified cluster sampling design to produce nationally representative data. In total, 13,354 respondents completed the survey interviews, which are in-person interviews administered by interviewers using hand-held devices. The overall response rate was 96\%. Key findings from and additional details of the survey methodology of GATS China are available in the GATS China fact sheet [23].

\subsection{Measures}

Knowledge of the harmful effects of smoking was assessed with three core questions: "Based on what you know or believe, does smoking tobacco cause the following: Stroke (blood clots in the brain that may cause paralysis)/Heart attack/Lung cancer"? In addition, knowledge of the harmful effect of SHS was measured by questions: "Based on what you know or believe, does breathing smoke from other people's cigarette cause the following: Heart disease in adult/Lung illness in children/ lung cancer in adult"? Participants who answered all three questions correctly were defined as have good knowledge; those who answered any of two questions correctly were defined as having some knowledge, and the rest were defined as have little knowledge.

In-home smoking bans were assessed by the sampled participant's reporting of smoking rules inside the home. Participants who reported that smoking was not allowed inside the home were classified as having a total smoking ban; those who reported smoking was not allowed but with exceptions to that rule were classified as having partial smoking ban; and those who reported that smoking was allowed or had no rules were defined as having no ban. Participants who reported working indoors were asked to describe the smoking policy at work. Workplace smoking rules were classified as a full ban, a partial ban, and no ban.

SHS exposure in public places was assessed by a set of questions that asked if participants had seen anyone smoking in government buildings, healthcare facilities, on public transportation, in restaurants and at schools during the past 30 days. Healthcare facilities were assessed by the questions that did 
anyone smoke inside of any "private/village health care facilities", "hospital or community health care facilities" or "other health care facilities". People who reported viewing smoking at any location above were defined as being exposed to SHS in public places.

Smoking status was defined by the question: "Do you currently smoke any tobacco product on a daily basis, less than daily, or not at all?" An adult who currently smoked any tobacco product daily or less than daily was defined as current smoker. Demographics variables included age (15-34 years; 35-44 years; 45-59 years; $\geq 60$ years), gender, highest attained education level ("primary school" or less; "secondary school" or less; "high school/technical secondary school"; "college" or higher), region (North; Northeast; East; Mid-south; Southwest; Northwest), urban/rural area, career type (agriculture workers; equipment operator or technician; business or service industry employee; leader of organizations; medical and health personnel; teacher; other), and wealth index. Wealth index was measured by principal component analysis based on a set of questions about whether a household has certain items, including electricity, flush toilet, fixed telephone, cell phone, television, radio, refrigerator, car, moped/scooter/motorcycle, washing machine, and air conditioner/heater [20]. Based on the results of a principal component analysis, the score of first principal component was divided into quintiles to classify a person's socioeconomic status [20].

\subsection{Statistical Analysis}

All statistical analyses were conducted using the survey functions in Stata 12.0 (Stata Corporation, College Station, TX, USA). The data were properly weighted using the personal weights, and the survey design features such as strata and clustering were accounted for in the analyses.

Descriptive statistics were calculated for the sample, by smoking status and gender. In addition, the knowledge level of the harmful effects of smoking and SHS exposure were assessed for the sample by demographic characteristics. The prevalence of in-home and workplace smoking bans were reported by household and geographic characteristics. In addition, the prevalence of viewing smoking in public places was estimated by geographic characteristics. Chi-square tests were used to analyze the differences in smoking and SHS related knowledge, smoking bans, and prevalence of viewing smoking in public places by corresponding dependent variables. Individuals who had incomplete information on wealth index variables, knowledge on smoking or SHS exposure, reported in-home or workplace smoking ban, or SHS exposure in public places were excluded from the corresponding analysis.

\section{Results}

Our study identified the factors related to better knowledge of the harmful effects of smoking and SHS exposure, smoking bans at home and workplaces and SHS exposure in public places. In addition to the existing studies on the topic, our study focused on geographic factors and socioeconomic status including education level, wealth index and career type.

Table 1 summarizes characteristics of 13,354 individuals who were representative of the 1,068,752,451 people aged 15 years and older in China. The weighted data suggests that $28.3 \%$ of individuals were current smokers, and approximately $95.8 \%$ of current smokers were male. More than half of males reported to be current smokers (52.9\%); among females, the smoking prevalence was $2.4 \%$. There was a difference in the age distribution between male and female smokers, with females being older than 
males. In addition, over half of the female smokers had an educational level lower or equal primary school. In contrast, the majority of the male smokers had an educational level greater than primary school. Moreover, the majority of the female smokers were agriculture workers and none of the female health personnel or teachers were smokers. Interestingly, more than one-third of female smokers were from Northeast China; however, less than $10 \%$ of male smokers were from that region.

Table 1. Characteristics of study population by smoking status and gender.

\begin{tabular}{|c|c|c|c|c|c|c|c|c|}
\hline \multirow{2}{*}{ Characteristics } & \multicolumn{4}{|c|}{$\begin{array}{c}\text { Current Smoker }{ }^{\mathrm{a}} \\
(28.3 \%)\end{array}$} & \multicolumn{4}{|c|}{$\begin{array}{c}\text { Non-smoker }^{\mathrm{a}} \\
(71.7 \%) \\
\end{array}$} \\
\hline & $\begin{array}{c}\text { Male } \\
(95.8 \%)\end{array}$ & $\begin{array}{c}\text { Female } \\
(4.2 \%)\end{array}$ & Total & $p$ Value & $\begin{array}{c}\text { Male } \\
(33.4 \%)\end{array}$ & $\begin{array}{l}\text { Female } \\
(66.6 \%)\end{array}$ & Total & $p$ Value \\
\hline Age & & & & $<0.001 *$ & & & & $<0.001 *$ \\
\hline 15-34 Years & 30.3 & 7.7 & 29.4 & & 47.7 & 36.0 & 39.9 & \\
\hline 35-44 Years & 28.0 & 25.0 & 27.8 & & 17.7 & 25.0 & 22.6 & \\
\hline 45-59 Years & 29.0 & 32.8 & 29.2 & & 17.6 & 23.3 & 21.4 & \\
\hline$\geq 60$ Years & 12.7 & 34.5 & 13.6 & & 17.0 & 15.7 & 16.1 & \\
\hline Education & & & & $<0.001 *$ & & & & $<0.001 *$ \\
\hline$\leq$ Primary School & 22.0 & 59.4 & 23.5 & & 18.6 & 34.0 & 28.9 & \\
\hline$\leq$ Secondary School ${ }^{\mathbf{b}}$ & 44.8 & 24.0 & 44.0 & & 39.1 & 36.2 & 37.2 & \\
\hline $\begin{array}{l}\text { High School/Technical } \\
\text { Secondary School }^{\mathbf{b}}\end{array}$ & 23.2 & 10.7 & 22.7 & & 25.6 & 18.3 & 20.8 & \\
\hline$\geq$ College & 10.0 & 5.9 & 9.8 & & 16.7 & 11.4 & 13.2 & \\
\hline Urban/Rural & & & & 0.196 & & & & 0.226 \\
\hline Urban & 42.4 & 50.8 & 42.8 & & 49.3 & 46.4 & 47.4 & \\
\hline Rural & 57.6 & 49.2 & 57.2 & & 50.7 & 53.6 & 52.6 & \\
\hline Region & & & & $<0.001 *$ & & & & $0.018 *$ \\
\hline North & 13.0 & 16.2 & 13.2 & & 12.2 & 12.9 & 12.7 & \\
\hline Northeast & 9.6 & 36.0 & 10.7 & & 11.5 & 8.5 & 9.5 & \\
\hline East & 28.4 & 18.2 & 27.9 & & 34.3 & 30.5 & 31.8 & \\
\hline Mid-south & 18.2 & 8.5 & 17.8 & & 19.0 & 19.5 & 19.3 & \\
\hline Southwest & 23.9 & 18.7 & 23.7 & & 16.1 & 21.6 & 19.7 & \\
\hline Northwest & 6.9 & 2.4 & 6.7 & & 6.9 & 7.0 & 7.0 & \\
\hline Wealth Index & & & & 0.743 & & & & $0.024 *$ \\
\hline Lowest & 16.0 & 19.9 & 16.1 & & 16.0 & 15.3 & 15.5 & \\
\hline Low & 19.5 & 21.8 & 19.6 & & 14.8 & 18.8 & 17.5 & \\
\hline Middle & 20.7 & 18.5 & 20.6 & & 19.9 & 20.6 & 20.4 & \\
\hline High & 21.9 & 19.2 & 21.8 & & 21.3 & 21.1 & 21.2 & \\
\hline Highest & 21.9 & 20.6 & 21.9 & & 28.0 & 24.2 & 25.4 & \\
\hline
\end{tabular}


Table 1. Cont.

\begin{tabular}{|c|c|c|c|c|c|c|c|c|}
\hline \multirow{2}{*}{ Characteristics } & \multicolumn{4}{|c|}{$\begin{array}{c}\text { Current Smoker }{ }^{\mathrm{a}} \\
(28.3 \%)\end{array}$} & \multicolumn{4}{|c|}{$\begin{array}{c}\text { Non-smoker }{ }^{\mathrm{a}} \\
(\mathbf{7 1 . 7 \% )}\end{array}$} \\
\hline & $\begin{array}{c}\text { Male } \\
(95.8 \%)\end{array}$ & $\begin{array}{l}\text { Female } \\
(4.2 \%)\end{array}$ & Total & $p$ Value & $\begin{array}{c}\text { Male } \\
(33.4 \%)\end{array}$ & $\begin{array}{l}\text { Female } \\
(66.6 \%)\end{array}$ & Total & $p$ Value \\
\hline Career & & & & $<0.001 *$ & & & & $<0.001 *$ \\
\hline $\begin{array}{l}\text { Agriculture } \\
\text { workers }\end{array}$ & 34.2 & 41.0 & 34.5 & & 25.2 & 33.1 & 30.5 & \\
\hline $\begin{array}{l}\text { Equipment } \\
\text { operator/Technician }\end{array}$ & 26.2 & 1.7 & 25.1 & & 17.2 & 7.5 & 10.8 & \\
\hline $\begin{array}{l}\text { Business/Service } \\
\text { industry employee }\end{array}$ & 16.8 & 10.5 & 16.5 & & 13.0 & 16.5 & 15.3 & \\
\hline $\begin{array}{l}\text { Leader of } \\
\text { organizations }\end{array}$ & 6.7 & 6.5 & 6.7 & & 6.4 & 3.7 & 4.6 & \\
\hline $\begin{array}{l}\text { Medical/ } \\
\text { Health personnel }\end{array}$ & 1.0 & 0.0 & 1.0 & & 1.7 & 2.1 & 1.9 & \\
\hline Teacher & 0.8 & 0.0 & 0.8 & & 1.7 & 2.0 & 1.9 & \\
\hline Other & 14.3 & 40.4 & 15.4 & & 34.8 & 35.1 & 35.0 & \\
\hline
\end{tabular}

Notes: ${ }^{\text {a }}$ : All percentages were weighted using personal weights, survey strata and primary sampling units (PSUs) information; ${ }^{\mathbf{b}}$ : Secondary school in China is equivalent to middle school or junior high school in the U.S. (usually cover grade 7-9); High School/Technical Secondary School is equivalent to senior high school in the U.S. (usually cover grade $10-12$ ); $*$ : $p$ Value $<0.05$.

The information in Table 2 relates knowledge to age, gender, educational level, career type and smoking status. Over half of the population had little knowledge of the harmful effects of smoking (56.8\%) and SHS exposure (51.5\%). In contrast, only about $22.1 \%$ of the target population had good knowledge of the harmful effects of smoking, and $24.6 \%$ had good knowledge related to SHS exposure. Non-smokers appeared to be more aware of the harm of smoking $(p=0.002)$ and SHS $(p<0.001)$ compare to smokers. Approximately $23.0 \%$ of non-smokers had good knowledge of smoking, and $25.6 \%$ had good knowledge of SHS. Among current smokers, $19.6 \%$ and $22.1 \%$ had good knowledge of smoking and SHS, respectively.

Younger individuals appeared to have better knowledge of the harmful effects of smoking $(p=0.004)$ and SHS exposure $(p<0.001)$. Near $60 \%$ of people aged between 15 and 34 had some or good knowledge of SHS exposure, while among people greater than 60 years old, only $32.5 \%$ had some or good knowledge of SHS exposure. In general, the awareness of the harmful effects of smoking $(p=0.045)$ and SHS exposure $(p=0.044)$ among females was not as good as it was among males. People who were better educated tended to be more aware of the harmful effects of smoking $(p<0.001)$ and SHS $(p<0.001)$. Among people had attended primary school or less, $70.8 \%$ and $75.1 \%$ had little knowledge about smoking and SHS exposure, respectively. In contrast, among people had attended college or higher, $64.6 \%$ and $77.1 \%$ had some or good knowledge of smoking and SHS, respectively. Moreover, nearly $70 \%$ of agriculture workers had little knowledge of the harmful effects of smoking and SHS. In contrast, medical/health personnel and teachers had better knowledge, with the majority of medical/health personnel having good knowledge. 
Table 2. Knowledge of harm effects of smoking and SHS exposure.

\begin{tabular}{|c|c|c|c|c|c|c|c|c|}
\hline \multirow[b]{2}{*}{ Characteristics } & \multicolumn{4}{|c|}{ Smoking Knowledge ${ }^{\text {a }}$} & \multicolumn{4}{|c|}{ SHS Exposure Knowledge ${ }^{\text {a }}$} \\
\hline & $\begin{array}{c}\text { Little } \\
(56.8 \%) \\
\end{array}$ & $\begin{array}{c}\text { Some } \\
(21.1 \%) \\
\end{array}$ & $\begin{array}{c}\text { Good } \\
(22.1 \%) \\
\end{array}$ & $p$ Value & $\begin{array}{c}\text { Little } \\
(51.5 \%) \\
\end{array}$ & $\begin{array}{c}\text { Some } \\
(23.9 \%) \\
\end{array}$ & $\begin{array}{c}\text { Good } \\
(24.6 \%) \\
\end{array}$ & $p$ Value \\
\hline Age & & & & $0.004 *$ & & & & $<0.001 *$ \\
\hline 15-34 Years & 54.1 & 24.0 & 22.0 & & 40.9 & 32.1 & 27.0 & \\
\hline 35-44 Years & 58.3 & 21.1 & 20.6 & & 50.8 & 23.3 & 26.0 & \\
\hline 45-59 Years & 57.3 & 19.0 & 23.7 & & 58.3 & 18.6 & 23.1 & \\
\hline$\geq 60$ Years & 61.1 & 16.8 & 22.1 & & 67.5 & 13.3 & 19.2 & \\
\hline Gender & & & & $0.045 *$ & & & & $0.044 *$ \\
\hline Male & 55.3 & 21.6 & 23.1 & & 50.2 & 24.0 & 25.8 & \\
\hline Female & 58.7 & 20.3 & 21.0 & & 52.8 & 23.8 & 23.4 & \\
\hline Education & & & & $<0.001 *$ & & & & $<0.001 *$ \\
\hline$\leq$ Primary School & 70.8 & 14.8 & 14.3 & & 75.1 & 12.6 & 12.4 & \\
\hline$\leq$ Secondary School ${ }^{\mathbf{b}}$ & 59.0 & 20.9 & 20.1 & & 52.4 & 24.4 & 23.2 & \\
\hline $\begin{array}{l}\text { High School/Technical } \\
\text { Secondary School }^{\mathbf{b}}\end{array}$ & 47.7 & 25.6 & 26.8 & & 35.9 & 31.5 & 32.6 & \\
\hline$\geq$ College & 35.4 & 27.2 & 37.4 & & 22.9 & 34.3 & 42.8 & \\
\hline Career & & & & $<0.001 *$ & & & & $<0.001 *$ \\
\hline Agriculture workers & 68.8 & 16.2 & 15.0 & & 69.5 & 15.6 & 14.9 & \\
\hline $\begin{array}{l}\text { Equipment } \\
\text { operator/Technician }\end{array}$ & 52.4 & 24.3 & 23.3 & & 44.5 & 30.8 & 24.7 & \\
\hline $\begin{array}{l}\text { Business/Service } \\
\text { Industry employee }\end{array}$ & 58.6 & 21.9 & 19.5 & & 47.1 & 28.6 & 24.3 & \\
\hline Leader of organizations & 39.9 & 22.3 & 37.8 & & 35.1 & 26.1 & 38.8 & \\
\hline Medical/Health personnel & 20.2 & 23.9 & 55.8 & & 17.2 & 20.5 & 62.3 & \\
\hline Teacher & 39.2 & 26.5 & 34.3 & & 21.9 & 31.4 & 46.7 & \\
\hline Other & 51.7 & 23.3 & 25.0 & & & & & \\
\hline Smoking Status & & & & $0.002 *$ & & & & $<0.001 *$ \\
\hline Non-smoker & 55.2 & 21.7 & 23.0 & & 49.6 & 24.8 & 25.6 & \\
\hline Current Smoker & 61.3 & 19.1 & 19.6 & & 56.3 & 21.6 & 22.1 & \\
\hline
\end{tabular}

Notes: ${ }^{a}$ : All analyses were weighted using personal weights, survey strata and PSUs information;

b: Secondary school in China is equivalent to middle school or junior high school in the U.S. (usually cover grade 7-9); High School/Technical Secondary School is equivalent to senior high school in the U.S. (usually cover grade $10-12$ ); * $p$ Value $<0.05$.

Table 3 contains information on the implementation of indoor smoking bans in homes and at workplaces in China. In total, about $9.3 \%$ of the households had a full smoking ban, $12.1 \%$ had partial ban, and $78.6 \%$ of the households had no restrictions on smoking in home. Households in urban areas $(p<0.001)$ and higher income households $(p<0.001)$ had a higher prevalence of in-home smoking bans. The implementation of in-home smoking bans was not statistically different by regions $(p=0.142)$. At workplaces, the status of smoking bans did not differ by region or urban $v s$. rural areas. However, people who are equipment operators or technicians and people who work in business or the service industry were less likely to be protected by smoking bans at work. In contrast, medical/health personnel and teachers were more likely to report a full ban at work. 
Among the various public places, the prevalence of viewing smoking in restaurants was the highest (89.4\%), followed by government buildings (59.6\%), healthcare facilities (38.8\%), schools (37.7\%) and public transportation vehicles (34.4\%) (Table 4). The prevalence of exposure to smoking in healthcare facilities and on public transportation was higher in rural areas than in urban areas. About $67 \%$ of respondents reported seeing smoking in healthcare facilities in rural $v s .33 \%$ in urban areas; $42.3 \%$ of respondents were exposed to smoking in public transportation vehicles in rural areas vs. $27 \%$ in urban areas. Exposure to smoking at restaurants and schools was not different in rural and urban areas. In addition, the Southwest region had the worst smoking environment at government buildings, healthcare facilities and public transportation, followed by the Mid-south and the Northeast.

Table 3. Prevalence of smoking bans in home and at workplaces.

\begin{tabular}{|c|c|c|c|c|c|c|c|c|}
\hline \multirow[b]{2}{*}{ Characteristics } & \multicolumn{4}{|c|}{ In-Home Smoking Ban $(n=13,308)^{a}$} & \multicolumn{4}{|c|}{ Workplace Smoking Ban $(n=4431)^{a}$} \\
\hline & $\begin{array}{c}\text { Full } \\
(9.3 \%)\end{array}$ & $\begin{array}{l}\text { Partial } \\
(12.1 \%) \\
\end{array}$ & $\begin{array}{l}\text { No Ban } \\
(78.6 \%) \\
\end{array}$ & $p$ Value & $\begin{array}{c}\text { Full } \\
(28.8 \%) \\
\end{array}$ & $\begin{array}{l}\text { Partial } \\
(30.4 \%) \\
\end{array}$ & $\begin{array}{l}\text { No Ban } \\
(\mathbf{4 0 . 8 \% )} \\
\end{array}$ & $p$ Value \\
\hline Urban/Rural & & & & $<0.001$ * & & & & 0.079 \\
\hline Urban & 13.4 & 18.5 & 68.1 & & 30.7 & 31.7 & 37.6 & \\
\hline Rural & 5.8 & 6.7 & 87.6 & & 25.5 & 28.3 & 46.2 & \\
\hline Region & & & & 0.142 & & & & 0.064 \\
\hline North & 10.7 & 17.6 & 71.7 & & 39.4 & 26.6 & 34.0 & \\
\hline Northeast & 9.6 & 15.5 & 74.8 & & 28.9 & 33.6 & 37.5 & \\
\hline East & 10.8 & 12.2 & 77.0 & & 29.6 & 29.4 & 41.0 & \\
\hline Mid-south & 5.1 & 7.9 & 87.0 & & 28.2 & 28.1 & 43.7 & \\
\hline Southwest & 6.8 & 10.0 & 83.3 & & 18.0 & 37.4 & 44.6 & \\
\hline Northwest & 17.9 & 14.6 & 67.5 & & 29.5 & 27.4 & 43.1 & \\
\hline Wealth Index & & & & $<0.001 *$ & & & & - \\
\hline Lowest & 7.7 & 4.2 & 88.1 & & - & - & - & \\
\hline Low & 5.9 & 6.1 & 88.0 & & - & - & - & \\
\hline Middle & 8.0 & 12.0 & 80.0 & & - & - & - & \\
\hline High & 10.3 & 15.3 & 74.4 & & - & - & - & \\
\hline Highest & 12.8 & 18.9 & 68.3 & & - & - & - & \\
\hline Career $^{b}$ & & & & & & & & $<0.001 *$ \\
\hline $\begin{array}{l}\text { Equipment operator/ } \\
\text { Technician }\end{array}$ & - & - & - & & 26.9 & 30.8 & 42.3 & \\
\hline $\begin{array}{l}\text { Business/ Service } \\
\text { industry employee }\end{array}$ & - & - & - & & 23.6 & 26.3 & 50.1 & \\
\hline $\begin{array}{l}\text { Leader of } \\
\text { organizations }\end{array}$ & - & - & - & & 24.1 & 35.2 & 40.7 & \\
\hline $\begin{array}{l}\text { Medical/ Health } \\
\text { personnel }\end{array}$ & - & - & - & & 48.1 & 36.6 & 15.3 & \\
\hline Teacher & - & - & - & & 41.8 & 36.5 & 21.7 & \\
\hline Other & - & - & - & & 34.6 & 30.6 & 34.8 & \\
\hline
\end{tabular}

Notes: ${ }^{a}$ : All analyses were weighted using personal weights, survey strata and PSUs information;

b: Agriculture workers were excluded from the analysis because they usually work outdoors;

$*$ : $p$ Value $<0.05$. 
Table 4. Prevalence of viewing smoking in various public places.

\begin{tabular}{|c|c|c|c|c|c|}
\hline Characteristics & $\begin{array}{c}\text { Government } \\
\text { Buildings } \\
(\mathrm{n}=1289)\end{array}$ & $\begin{array}{c}\text { Healthcare } \\
\text { Facilities } \\
(n=4713)\end{array}$ & $\begin{array}{c}\text { Public } \\
\text { Transportation } \\
(\mathrm{n}=\mathbf{6 5 6 9})\end{array}$ & $\begin{array}{c}\text { Restaurants } \\
(\mathrm{n}=\mathbf{5 8 0 8})\end{array}$ & $\begin{array}{c}\text { Schools } \\
(\mathrm{n}=2449)\end{array}$ \\
\hline Prevalence $(\%)$ & 59.6 & 38.8 & 34.4 & 89.4 & 37.7 \\
\hline \multicolumn{6}{|l|}{ Urban/Rural } \\
\hline Urban & 57.2 & 33.0 & 27.0 & 89.4 & 37.0 \\
\hline Rural & 62.5 & 67.0 & 42.3 & 89.4 & 38.5 \\
\hline$p$ Value & 0.524 & $0.030 *$ & $0.015 *$ & 0.993 & 0.686 \\
\hline \multicolumn{6}{|l|}{ Region } \\
\hline North & 45.3 & 26.1 & 19.1 & 87.9 & 30.2 \\
\hline Northeast & 66.3 & 38.3 & 31.6 & 88.9 & 28.4 \\
\hline East & 55.2 & 32.3 & 29.9 & 91.6 & 39.1 \\
\hline Mid-south & 53.4 & 41.2 & 37.6 & 87.4 & 39.1 \\
\hline Southwest & 75.7 & 54.5 & 48.6 & 90.6 & 42.0 \\
\hline Northwest & 46.2 & 32.9 & 28.4 & 85.1 & 38.5 \\
\hline$p$ Value & $0.017 *$ & $0.011 *$ & $0.024 *$ & 0.412 & 0.822 \\
\hline
\end{tabular}

Notes: All analyses were weighted using personal weights, survey strata and PSUs information; $* p$ Value $<0.05$

\section{Discussion}

Our results indicate that, among Chinese citizens age 15 years and older, there is poor knowledge of the harmful effects of tobacco, and knowledge varies with region and socioeconomic status. As a consequence, perhaps, over three-quarters of households reported having no smoking ban and a substantial number of workers, especially equipment operators and business industry employees, reported that their workplaces had no restriction on smoking. In addition, SHS exposure in public places is a significant problem in China. Restaurants were the major places where people reported being exposed, followed by government buildings, health facilities, schools, and public transportation.

Article 8 from the WHO FCTC requires parties to implement and enforce smoke-free policies to protect people from exposure to tobacco smoke [24]. However, results from our study suggest that implementation and enforcement of smoke-free policies in China is in great need of improvement. In 2010 , about $22.1 \%$ of people had good knowledge of smoking and health consequences, which was not that different from the level in 2002, three years before the FCTC was ratified in China [25]. The percentage of people with little knowledge of smoking effects in other low-and-middle income countries ranges from 5.1\% in Egypt to $33.1 \%$ in India [20]. Given our finding that $56.8 \%$ of Chinese people have little knowledge of the harmful effects of smoking, we can conclude that Chinese adults are much less aware than individuals living in low- and middle-income countries. Although medical/health personnel and teachers appeared to have better knowledge than the general Chinese population, still, about $20 \%$ of health personnel and $40 \%$ of teachers had limited awareness of the harmful effects of smoking. Health personnel and teachers are responsible for educating and disseminating health-related knowledge to patients, students and others. Enhancing their understanding should be a priority because it could ultimately improve knowledge among others in China. 
Knowing about the harmful effects of smoking and SHS exposure has been associated with adoption of in-home smoking bans; thus, this lack of knowledge that we found could partly explain our other finding that few homes had a complete in-home smoking ban [26]. The study found that $9.3 \%$ of households had full bans in home. Although this rate has been improved from the $6.3 \%$ in a 2004 survey, it is much lower than the 66\% reported among Chinese Americans in New York City [21,27]. A previous study has shown that Chinese parents lack knowledge of the health risk of SHS exposure, and the main reasons for not banning smoking in home were the social acceptability of smoking and the predominant influence of male family members [28]. In developed countries, by changing the social norms and attitudes toward smoking, the prevalence of in-home SHS exposure has decreased [29]. Implementing smoking bans in public places can be one approach to change the social norms surrounding tobacco use and subsequently lead to more smoking bans at home. The smoke-free air legislation in New York City is an example. After implementation of the law, the adoption rate of in-home smoking ban increased significantly [27]. In addition, having smoking bans at workplaces has a positive influence on adopting smoking bans at home. The percentage of adults who report working in a smoking-free environment in other low-and-middle income countries, ranges from $35 \%$ in Bangladesh to $83 \%$ in Uruguay [30]. Our finding that few people worked in smoke-free environments may also explain the low percentage of smoke-free homes. Although the Chinese government has ratified the FCTC in 2005, no national smoking bans in public places have been implemented. At the city level, Beijing, Shanghai, Guangzhou, Hong Kong, and some smaller cities have passed indoor smoking bans in public places. However, the policies are ambiguous, exclude workplaces and are not supported with adequate public education and enforcement [17].

The finding of widespread secondhand exposure in public places also suggests the need for implementation and enforcement of clean indoor air laws. Nearly $90 \%$ of participants reported seeing smoking in restaurants, and smoking was reported to be seen in healthcare facilities, on public transportation and in schools. In general, the prevalence of SHS exposure in public places appeared to be higher in the Southwest, Northeast and rural areas. The high prevalence of SHS exposure in rural areas and Southwest China may be due to the imbalanced implementation of indoor smoking bans, cultural influences on smoking behavior and toleration of SHS exposure. China has a unique smoking culture. For instance, smoking and serving cigarettes is considered as good business manners; tobacco products are popular gifts of respect on both formal and informal occasions. Our finding that a majority of the business and service industry employees worked at places without any smoking restriction may also explain such smoking culture. In general, there is little social stigma against smoking, especially in rural areas, where people tend to have a lower educational level and a higher smoking prevalence [23]. Culturally tailored strategies are needed to address this problem by geographic region and within specific populations, such as people of lower socioeconomic status, lower educational level and people living in rural areas. However, China's tobacco industry generates nearly $10 \%$ of government revenue each year, which makes the Chinese government itself the biggest stakeholder of such tobacco control strategies [31]. The Gross Domestic Product-first guideline of China, along with the widespread social acceptability of tobacco use and high smoking prevalence, may hinder the adoption and implementation of the tobacco control strategies [32].

Our study supports previous findings and provides updated information. We used nationally representative GATS data from China. The overall response rate was $96 \%$, which indicates a good 
representation of the Chinese population. However, we relied on self-reported data on people's smoking behavior, their in-home and workplace smoking bans, and exposure to secondhand smoke in public places. Although there is no information on biomarkers of cigarette smoking or exposure to secondhand smoke, these self-reported measures have been found to be valid and reliable in population-based studies [33]. In addition, there are only three questions to assess knowledge of the harmful effects of smoking or SHS exposure. It may limit our capability of assessing knowledge in a comprehensive way. Finally, because of the within-household sampling method used to select respondents, we were unable to associate personal characteristics, such as smoking behavior and knowledge of the harmful effects of smoking and SHS, to household smoking bans. Thus, in the future, it will be important to examine how knowledge of an individual relates to the choice to implement a household smoking ban.

\section{Conclusions}

In conclusion, this study suggests that Chinese individuals are not well informed of the risks associated with smoking and SHS and that they are regularly exposed to SHS at home, at work, and in other public places. Low knowledge and exposure are even more prevalent among people with a low socioeconomic status and those living in rural areas. The Chinese government needs to develop targeted educational and tobacco control programs to fit the cultural and social needs for Chinese citizens.

\section{Author Contributions}

Yue Jin, Ling Wang, Bo Lu and Amy K. Ferketich work together. Specifically, Yue Jin brings the idea, conducts statistical analyses and interprets the results. Ling Wang provides insights for literature guidance and results interpretation. Bo Lu provides guidance on all statistical analyses. Amy K. Ferketich provides insights for literature guidance, results interpretation and policy implications to this study.

\section{Conflicts of Interest}

The authors declare no conflict of interest.

\section{References}

1. The Health Consequences of Involuntary Exposure to Tobacco Smoke: A report of the Surgeon General; Office on Smoking and Health, Centers for Disease Control and Prevention: Atlanta, GA, USA, 2006.

2. Eisner, M.D.; Smith, A.K.; Blanc, P.D. Bartenders' respiratory health after establishment of smoke-free bars and taverns. JAMA 1998, 280, 1909-1914.

3. Centers for Disease Control and Prevention. Reduced secondhand smoke exposure after implementation of a comprehensive statewide smoking ban-New York, 26 June 26 2003-30 June 2004. MMWR 2007, 56, 705-708.

4. Evans, K.A.; Sims, M.; Judge, K.; Gilmore, A. Assessing the knowledge of the potential harm to others caused by second-hand smoke and its impact on protective behaviours at home. J. Public Health 2012, 34, 183-194. 
5. Blackburn, C.; Spencer, N.; Bonas, S.; Coe, C.; Dolan, A.; Moy, R. Effect of strategies to reduce exposure of infants to environmental tobacco smoke in the home: Cross-sectional survey. BMJ 2003, 327, doi:10.1136/bmj.327.7409.257.

6. Dunn, J.; Greenbank, S.; McDowell, M.; Mahoney, C.; Mazerolle, P.; Occhipinti, S.; Steginga, S. Community knowledge, attitudes and behaviours about environmental tobacco smoke in homes and cars. Health Promot. J. Aust. 2008, 19, 113-117.

7. WHO Report on the Global Tobacco Epidemic: 2011; World Health Organization: Geneva, Swizerland, 2011.

8. Au, W.W.; Su, D.; Yuan, J. Cigarette smoking in China: Public health, science, and policy. Rev. Environ. Health 2012, 27, 43-49.

9. Niu, S.R.; Yang, G.H.; Chen, Z.M.; Wang, J.L.; Wang, G.H.; He, X.Z.; Schoepff, H.; Boreham, J.; Pan, H.C.; Peto, R. Emerging tobacco hazards in China: 2. Early mortality results from a prospective study. BMJ 1998, 317, 1423-1424.

10. Callinan, J.E.; Clarke, A.; Doherty, K.; Kelleher, C. Legislative smoking bans for reducing secondhand smoke exposure, smoking prevalence and tobacco consumption. Cochrane Database Syst. Rev. 2010, 4, doi:10.1002/14651858.CD005992.pub2.

11. Britton, J.; Bogdanovica, I. Tobacco control efforts in Europe. Lancet 2013, 381, 1588-1595.

12. Jarvis, M.J.; Sims, M.; Gilmore, A.; Mindell, J. Impact of smoke-free legislation on children's exposure to secondhand smoke: Cotinine data from the health survey for England. Tob. Control 2012, $21,18-23$.

13. Fong, G.T.; Craig, L.V.; Guignard, R.; Nagelhout, G.E.; Tait, M.K.; Driezen, P.; Kennedy, R.D.; Boudreau, C.; Wilquin, J.L.; Deutsch, A.; et al. Evaluating the effectiveness of France's indoor smoke-free law 1 year and 5 years after implementation: findings from the itc france survey. PLoS One 2013, 8, doi:10.1371/journal.pone.0066692.

14. Fong, G.T.; Hyland, A.; Borland, R.; Hammond, D.; Hastings, G.; McNeill, A.; Anderson, S.; Cummings, K.M.; Allwright, S.; Mulcahy, M.; et al. Reductions in tobacco smoke pollution and increases in support for smoke-free public places following the implementation of comprehensive smoke-free workplace legislation in the Republic of Ireland: Findings from the ITC Ireland/ UK Survey. Tob. Control. 2006, 15, S51-S58.

15. Hahn, E.J. Smokefree legislation: A review of health and economic outcomes research. Amer. J. Prev. Med. 2010, 39, S66-S76.

16. Xiao, L.; Yang, Y.; Li, Q.; Wang, C.X.; Yang, G.H. Population-based survey of secondhand smoke exposure in China. Biomed. Environ. Sci 2010, 23, 430-436.

17. Parry, J. China pushes ahead with ban on indoor smoking. BMJ 2011, 342, doi:10.1136/bmj.d2314.

18. Yang, G.H.; Li, Q.; Wang, C.X.; Hsia, J.; Yang, Y.; Xiao, L.; Yang, J.; Zhao, L.H.; Zhang, J.; Xie, L. Findings from 2010 global adult tobacco survey: Implementation of MPOWER policy in China. Biomed. Environ. Sci. 2010, 23, 422-429.

19. King, B.A.; Mirza, S.A.; Babb, S.D.; Group, G.C. A cross-country comparison of secondhand smoke exposure among adults: Findings from the Global Adult Tobacco Survey (GATS). Tob. Control 2013, 22, doi:10.1136/tobaccocontrol-2012-050582 . 
20. Palipudi, K.M.; Gupta, P.C.; Sinha, D.N.; Andes, L.J.; Asma, S.; McAfee, T. Social determinants of health and tobacco use in thirteen low and middle income countries: Evidence from global adult tobacco survey. PLoS One 2012, 7, doi:10.1371/journal.pone.0033466.

21. Wang, C.P.; Ma, S.J.; Xu, X.F.; Wang, J.F.; Mei, C.Z.; Yang, G.H. The prevalence of household second-hand smoke exposure and its correlated factors in six counties of China. Tob. Control 2009, 18, 121-126.

22. Wei, X.; Zhang, Z.; Song, X.; Xu, Y.; Wu, W.; Lao, X.; Ma, W. Household smoking restrictions related to secondhand smoke exposure in Guangdong, China: A population representative survey. Nicotine Tob. Res. 2014, 16, 390-396.

23. World Health Organization. Global Adults Tobacco Survey (GATS) China Fact Sheet. Available online: http://www.who.int/tobacco/surveillance/en_tfi_china_gats_factsheet_2010.pdf (accessed on 20 April 2014).

24. World Health Organization. Guidelines for Implementation of Article 8. Available online: http://www.who.int/fctc/guidelines/adopted/article_8/en/ (accessed on 20 April 2014).

25. Yang, G.H.; Ma, J.M.; Liu, N.; Zhou, L.N. Smoking and passive smoking in Chinese, 2002. Zhonghua Liu Xing Bing Xue Za Zhi 2005, 26, 77-83. (in Chinese)

26. Centers for Disease Control. Prevention. State-specific prevalence of smoke-free home rulesUnited States, 1992-2003. MMWR 2007, 56, 501-504.

27. Shelley, D.; Fahs, M.C.; Yerneni, R.; Qu, J.; Burton, D. Correlates of household smoking bans among Chinese Americans. Nicotine Tob. Res. 2006, 8, 103-112.

28. Abdullah, A.S.; Hua, F.; Xia, X.; Hurlburt, S.; Ng, P.; MacLeod, W.; Siegel, M.; Griffiths, S.; Zhang, Z. Second-hand smoke exposure and household smoking bans in Chinese families: A qualitative study. Health Soc. Care Community 2012, 20, 356-364.

29. Chapman, S.; Freeman, B. Markers of the denormalisation of smoking and the tobacco industry. Tob. Control 2008, 17, 25-31.

30. Nazar, G.P.; Lee, J.T.; Glantz, S.A.; Arora, M.; Pearce, N.; Millett, C. Association between being employed in a smoke-free workplace and living in a smoke-free home: Evidence from 15 low-and middle-income countries. Prev. Med. 2014, 59, 47-53.

31. Li, C. The political mapping of China's tobacco industry and anti-smoking campaign. In Thornton China Center Monograph Series; John, L., Ed.; The Brookings Institution: Washington, D.C., USA, 2012.

32. Jin, J. Why FCTC policies haven't been transferred in China: Domestic dynamics and tobacco governance. J. Health Polit. Policy Law 2014, 39, doi:10.1215/03616878-2682630 .

33. SRNT Subcommittee on Biochemical Verification. Biochemical verification of tobacco use and cessation. Nicotine Tob. Res. 2002, 4, 149-159.

(C) 2014 by the authors; licensee MDPI, Basel, Switzerland. This article is an open access article distributed under the terms and conditions of the Creative Commons Attribution license (http://creativecommons.org/licenses/by/4.0/). 